\title{
Does Demand Uncertainty Moderate the Relationship of Risk Attitude and Sticky Cost? Evidence From Egypt
}

\author{
Ahmed M. Abdelhamid ${ }^{1}$ \\ ${ }^{1}$ Faculty of Commerce, Zagazig University, Zagazig, Egypt \\ Correspondence: Ahmed M. Abdelhamid, Faculty of Commerce, Accounting Department, Zagazig University, \\ Zagazig, Egypt. Tel: 20-122-642-0080.
}

Received: December 17, 2020

Accepted: January 23, $2021 \quad$ Online Published: February 20, 2021

doi:10.5430/ijfr.v12n3p356

URL: https://doi.org/10.5430/ijfr.v12n3p356

\begin{abstract}
The current paper explores the relation between managers' risk attitude and cost stickiness behavior and the role of demand uncertainty as a moderation variable in the Egyptian business environment. Managers' risk attitudes are measured using Bo and Sterken (2007) proxy measure [Bo, H., \& Sterken, E. (2007). Attitude towards risk, uncertainty, and fixed investment. The North American Journal of Economics and Finance, 18(1), 59-75]. Demand uncertainty is measured by the standard deviation of firms' sales over the sample period. The study sample includes 114 Egyptian-listed firms over a 14-year period (2004 - 2017) which results in 1,419 firm-year observations. The study models are estimated using the ordinary least squares (OLS) with a fixed-effects model. Findings show that in the presence of high demand uncertainty, risk-averse managers respond to sales decrease by cutting resources which lowers cost stickiness. One of the limitations is that some factors like firms' policies, corporate governance mechanisms, and board of directors' characteristics could dilute the effect of manager's risk attitude on cost stickiness. The current research emphasizes the importance of considering the firm's operating environment when selecting a manager for the firm, and the role of directed training to align the manager's personal characteristics with the firm's objectives. The current research contributes to the previous literature by documenting the effect of manager's risk attitude on cost stickiness and the role of a firm's demand uncertainty as a moderating variable between these two variables.
\end{abstract}

Keywords: sticky cost, risk attitude, demand uncertainty, Egyptian firms, cost behavior

\section{Introduction}

Since Anderson, Banker, and Janakiraman (2003) empirical evidence on sticky cost behavior which attributes some of the costs behavior to managers' decisions, a rapid stream of research has documented various factors and determinants of such behavior. The main cause of cost stickiness is that during sales decreasing periods, costs do not proportionally follow sales fall magnitude, i.e., costs decline at a slower rate. In other words, costs become sticky.

Anderson et al. (2003) state that the main reason for cost stickiness is the manager's comparison between adjustment costs and costs of bearing slack resources which are named "retention costs" by Brüggen and Zehnder (2014). To expand this comparison, psychological variables and manager's incentives magnify or diminish costs on both sides i.e., adjustment costs and retention costs. According to the theory, on average, adjustment costs are higher than retention costs.

Previous studies document manager's personal characteristics as a major determinant of this asymmetric cost behavior. These comprise the manager's incentives, related agency considerations, and individual attributes. If a manager acts as a self-interested agent, he/she will adjust resources in a way that maximizes his/her utility. Empire building will discourage the manager to cut unneeded resources (Chen, Lu, \& Sougiannis, 2012). Manager's overconfidence and hubris are found to be related to larger cost stickiness (Chen, Gores, \& Nasev, 2013; Qin, Mohan, \& Kuang, 2015; Yang, 2015). Managerial incentives that are tied with achieving the target will induce managers to cut costs quickly to meet or beat the target profit. Some papers differentiate between good cost stickiness and bad cost stickiness depending on the type of management compensation, whether it is equity-based compensation or fixed salary (Banker, Jin, \& Mehta, 2016; Brüggen \& Zehnder, 2014; Kama \& Weiss, 2013; Wiersma, 2012). Others find a relation between individual's attributes which include gender, age, and tenure and cost stickiness (Liang, Zhao, \& Wang, 2015). Previous literature tests the effect of managers' personal attributes on cost stickiness without 
considering the risk of the firm's operating environment, however, March and Shapira (1987) state that operating under risk will motivate managers to express their attitudes in firms' operations. The current study alleviates this by interacting demand uncertainty with managers risk attitude measure. Assessment of individual risk attitude is central to managerial and financial decision making (Fellner \& Maciejovsky, 2007). Manger's risk attitude is signaled in previous sticky cost literature using individual attributes or incentive type (Aboody, Levi, \& Weiss, 2018; Liang et al., 2015), which is considered indirect measures of risk attitude. The current study will expand on testing the relation between manager's risk attitude and cost stickiness by applying Bo and Sterken (2007) financial measure, which is constructed as a direct indicator of managers' risk attitude.

The current study contribution to the sticky cost literature is twofold. First, it applies a new direct financial measure of managers' risk attitudes. Second, it demonstrates the role of high demand uncertainty as an interaction variable with the risk attitude on cost stickiness. Furthermore, the results of this study can be seen as an extension of the extant literature in other countries.

The remainder of this paper is organized as follows. Section 2 contains literature review and the development of the research hypotheses. Section 3 details the research method. In section 4, the results of hypotheses testing are presented and discussed. Section 5 provides the conclusion and summary of the research, along with limitations and suggestions for future research.

\section{Literature Review and Hypotheses Development}

\subsection{Literature Review}

\subsubsection{Risk Attitude}

The "Upper Echelon theory" by Hambrick and Mason (1984) states that organizational actions and strategic choices are partially predicted by management characteristics and backgrounds. Furthermore, recent research suggests that manager's personal characteristics influence corporate policies. Cronqvist, Makhija, and Yonker, (2012) find a robust correlation between managers' personal leverage decisions and their firms' leverage policies. Overconfidence and the previous background of the manager affect corporate policies (Malmendier \& Nagel, 2011; Malmendier, Tate, \& Yan, 2011).

Risk attitude is considered one of the inherent personality traits. Furthermore, the same situation may be processed with different decisions depending on the decision maker's attitude toward risk (Hillson \& Murray-Webster, 2017). Therefore, the manager's attitude mainly contributes to shaping the firm's behavior and policies and predicting economic behavior (Dohmen et al., 2011).

Risk attitude can be defined as the state of mind or a generic orientation that is related to personality developments or culture (Hillson \& Murray-Webster, 2017; March \& Shapira, 1987; Rohrmann, 2005). This state of mind determines the response to a specific uncertainty. Simply, risk attitude shows the individual's chosen response to situations involving risk. Literature (e.g., Concina, 2014; Hillson \& Murray-Webster, 2017; Rieger, Wang, \& Hens, 2015; Rohrmann, 2005; Weber, 2010) always distinguishes between three types of risk attitudes: Risk-averse, risk-taker, and risk-neutral. The same three types are differentiated through current research risk attitude measure.

\subsubsection{Sticky Cost}

Sticky cost refers to the costs behavior when the rate of increase in cost in response to a given percentage increase in activity is higher than the rate of decrease in cost in response to an equivalent percentage decrease in activity. The cost stickiness framework moves the thinking of costs as a mechanical relationship between costs and activities to a more complicated process that subjects to different factors. Following Anderson et al. 2003, many studies document cost stickiness behavior in different economies and industries. In the Egyptian context, different studies document the cost stickiness behavior and factors affecting it (e.g., Abdelhamid \& Abulezz, 2019; Ibrahim \& Ezat, 2017).

In cost stickiness literature, there is one stream of studies that tests the relation between managers' personal attributes and cost stickiness behavior. An overconfident manager will have an overestimation of future sales which results in retaining a higher amount of slack resources when sales decline, which finally ends up with higher cost stickiness. Chen et al. (2013) distinguish the overconfident managers by their option exercise timing, as overconfident managers have the tendency to delay their option exercise time until firms' values increase as they expected. Qin et al. (2015) measure overconfidence by the prominence of the CEO's photograph in the firm's financial report. Yang (2015) depends on the hubris theory that argues that an overconfident manager will involve him/herself in takeover actions without giving high concern to the resulting profit. Yang (2015) finds that optimistic successful CEOs in merger synergies will have higher cost stickiness in their firms. 
Liang et al. (2015) test whether the manager's personal characteristics will affect the cost stickiness of listed companies in China. They employ gender, age, and tenure as differential factors of the manager's personal characteristics. They build their hypothesis based on previous research findings that female managers tend to bear lower risks than male managers. The same is found concerning the age of the manager. Older managers take more conservative decisions while younger managers express themselves in risky ones (Prendergast \& Stole, 1996). Literature also states that managers with long-term service tend to apply conservative policies. As they expect, male and younger managers' firms have a higher level of cost stickiness. However, they do not confirm a significant relation between management tenure and cost stickiness degree.

In a cross-country study, Kitching, Mashruwala, and Pevzner (2016) examine how five dimensions of national culture affect the cost stickiness behavior and the managers' decisions to cut resources. Uncertainty avoidance refers to cultures where individuals feel uncomfortable with uncertainty or unknowns (Kitching et al., 2016). Managers who operate in this culture focus on the current sales decrease ignoring the future probability of demand increase again. Managers, in uncertainty avoidance cultures, mainly use short-term sales expectations which will result in lower cost stickiness degree. As expected, cost sticky behavior is less marked in countries where higher uncertainty avoidance culture is dominant.

Studies that test the relation between manager's risk attitude and sticky cost fail to consider the effect of firm's risk on this relation. Manager's risk attitude is explicitly demonstrated when there is a risk in firm's operations (March and Shapira; 1987). Previous literature differentiates between two types of firm risks, variability risk, and downside risk (Miller \& Chen, 2004; Rego, Billett, \& Morgan, 2009). Variability risk is measured by standard deviation and/or the aggressiveness and consistency of financial and operational firm policies. Downside risk concentrates on negative outcomes. The current study employs demand standard deviations as a measure of firm risk. Moreover, the cultural difference between the current study business environment and previous studies business environments is a factor that deserves investigation.

\subsection{Hypotheses Development}

The main objective of the current study is to test the effect of management's risk attitude on cost stickiness. To provide a baseline for the remaining hypotheses, the average cost stickiness hypothesis is tested first.

During sales decrease periods managers compare the retention costs with the adjustment costs. Adjustment costs include the current period's costs of cutting resources and the future costs that are required to counterbalance resources in case of sales rebound. From the prospect theory perspective (Kahneman \& Tversky, 1979), giving that sales in the previous period are the statues que "reference point", sales decrease means managers will be in a loss situation. According to prospect theory, individuals are risk-taker in a loss situation. This means managers will tend to bear the risk of slack resources for the current period rather than cutting them. Therefore, operating costs will be sticky on average which will be tested in the following hypothesis:

H1: Egyptian firms' operating expenses are sticky.

In the sticky cost framework, previous studies test the effect of managers' attitudes on cost stickiness. Papers like Chen et al. (2013), Kitching et al. (2016), Liang et al. (2015), Qin et al. (2015), Yang (2015) test for the effect of managers' attributes and characteristics on cost stickiness degree. They show that managers' overconfidence or overvaluation of future performance can increase cost stickiness and vice versa. Aboody et al. (2018) document that a change in managers' risk-taking incentive leads to an adjustment of firms operating leverage's components.

The expected utility theory suggests that risk-averse persons will prefer known amounts to uncertain equivalent amounts (Concina, 2014). In a sticky cost framework, risk-averse managers will prefer to cut resources and bear a certain amount of loss rather than keeping the current capacity level to obtain a probable future gain. Therefore, the following hypothesis is tested:

H2: Faced with a decline in demand, a risk-averse manager will cut resources more quickly than will a risk-taker manager.

Bo and Sterken (2007) find that different managers' risk attitudes lead to different responses to demand uncertainty. They find that under demand uncertainty risk-averse managers will downsize investment, while risk-taking managers will undertake investment. Higher demand uncertainty means a wider range of both sales increase and sales decrease around the mean.

It is noted that expected utility theory and prospect theory yield conflicting predictions concerning managers responses with regard to demand decline. Expected utility theory predicts no cost stickiness in declining demand 
situations whereas prospect theory predicts cost stickiness in those situations. This conflict may be resolved by invoking demand uncertainty as a moderator of the relationship between risk attitude and cost stickiness.

H3: The level of demand uncertainty will moderate the relation between managers' attitudes toward risk and cost stickiness.

\section{Methodology}

\subsection{Study Population and Sample}

The study's population is all listed Egyptian corporations, except for banks, financial services, and real estate industry sectors which are excluded because of their special nature and following previous literature (eg., Anderson et al., 2003; Banker \& Byzalov, 2014; He, Teruya, \& Shimizu, 2010).

A sample of 117 firms over 14 years (2004 - 2017) is drawn from the population. Missing observations of operating costs or sales revenues are excluded. Furthermore, firms for which risk coefficient cannot be calculated are discarded from the sample. After these procedures, the sample observations decrease from 1,511 to 1,419 for 114 firms. To alleviate the inflation problem, all financial statement figures are deflated using the GDP deflator. The data are organized as an unbalanced panel data model due to firm-year observations that are deleted. The model is estimated using ordinary least squares (OLS) with fixed effect model with time dummies to control for the financial crisis and Egyptian revolution. Clustered standard errors per cross-section (Note 1) is used to dilute the bias in OLS standard error arising from cross-sectional independence, heteroskedasticity, and serial correlation (Gow, Ormazabal, \& Taylor, 2010). The regression is performed using STATA 14 and figures are created using E-views 10.

Figure 1 displays curves of both the mean of $\operatorname{Ln}\left(\frac{O E x_{i, t}}{O E x_{i, t-1}}\right)$ and the mean of $\operatorname{Ln}\left(\frac{\operatorname{Rev}_{i, t}}{\operatorname{Rev}_{i, t-1}}\right)$ for the whole sample observations from 2004 to 2017, where OEx stands for operating expenses and Rev stands for revenues. Figure 2 shows the two curves of operating expenses and revenues but only for the sales decline observations. As can be seen, the curve of the mean of $\operatorname{Ln}\left(\frac{O E x_{i, t}}{O E x_{i, t-1}}\right)$ is consistently higher than the curve of the mean of $\operatorname{Ln}\left(\frac{\operatorname{Rev} v_{i, t}}{\operatorname{Rev} v_{i, t-1}}\right)$, which explicitly reflects that the rate of decrease in operating expenses is lower than the rate of decrease in sales or revenues, i.e., sticky cost behavior. Figures 3 and 4 present the behavior of the same curves for risk-taker and risk-averse firms with demand uncertainty above the sample median. Comparing Figures 3 and 4, it can be shown that the area between the mean of $\operatorname{Ln}\left(\frac{O E x_{i, t}}{O E x_{i, t-1}}\right)$ curve and the mean of $\operatorname{Ln}\left(\frac{\operatorname{Rev}_{i, t}}{\operatorname{Rev}_{i, t-1}}\right)$ curve is wider for demand decrease periods in risk-taker firms under high demand uncertainty which roughly implies that sticky cost degree is higher. The observed breaks for Figures 3 and 4 are due to the lack of observations.

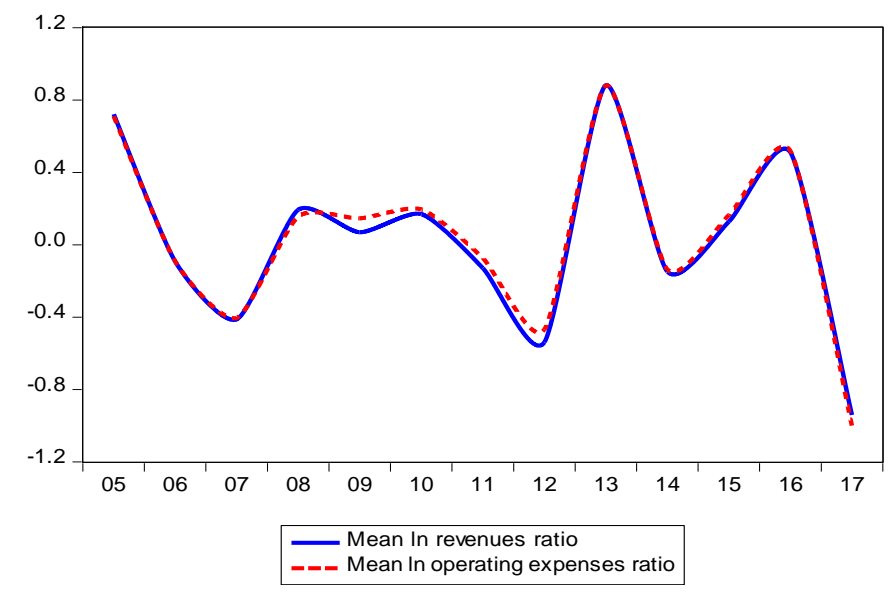

Figure 1. Full sample 


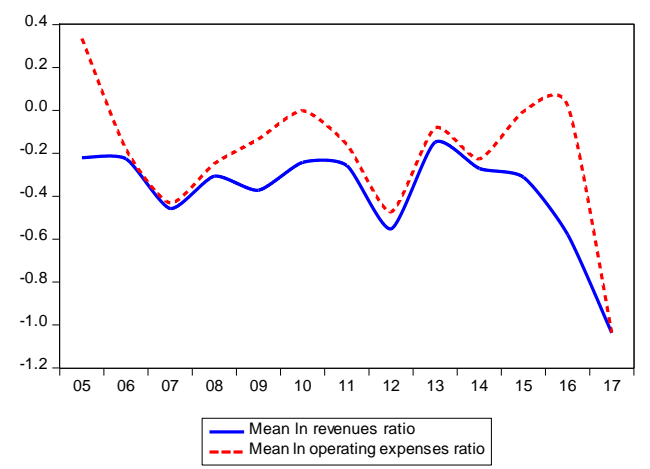

Figure 2. Full sample, decreasing sales periods

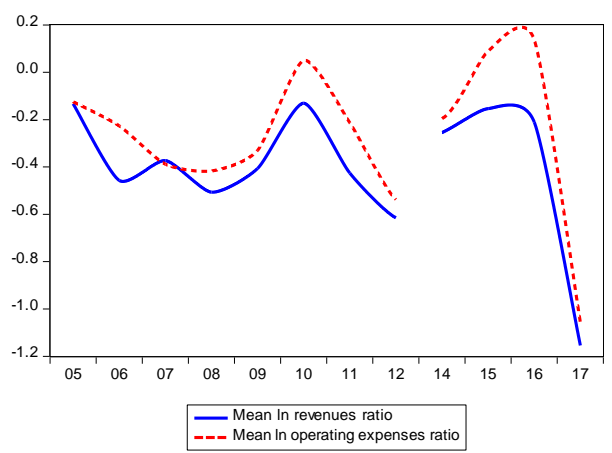

Figure 3. Decreasing sales periods for risk-taker firms with high demand uncertainty

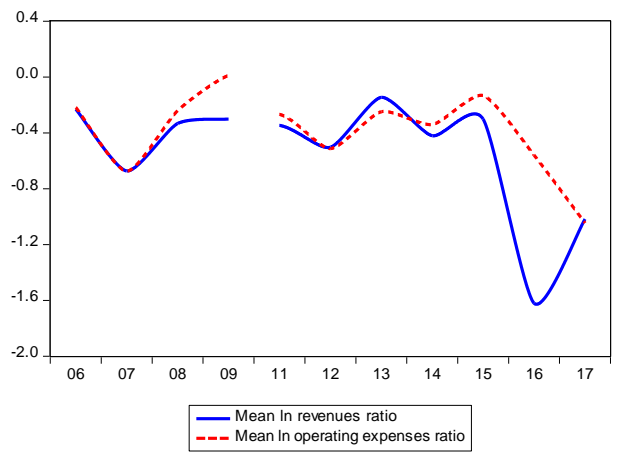

Figure 4. Decreasing sales periods for risk-averse firms with high demand uncertainty

\subsection{Measures}

Bo and Sterken (2007) measure of risk attitude

The managers' risk attitude financial measure which is introduced by Bo and Sterken (2007) is used. They use net income's skewness and standard deviations to calculate the firm's risk premium, then a proxy for managers' risk preference is calculated. To estimate managers' attitude toward risk on a firm by firm basis:

$$
P T_{t}^{R}=R A R+\alpha_{1} S D_{t}+\alpha_{2} S K E W_{t}
$$

Where $P T_{t}^{R} \equiv \frac{\text { Net Profit }}{\text { Total Assts }}$ refers to realized net income divided by total assets at time $t$ (i.e., realized profit rate); $R A R$ refers to the "risk-adjusted rate" of return is the regression constant; $S D_{t}$ refers to the standard deviation of the 
profit rate at time $t$; and $S K E W_{t}$ refers to the third moment of the profit rate (skewness). The standard deviations and the skewness are calculated based on the previous five years.

$R A R$ is a constant that represents all impacts on net income that are not reflected by the standard deviation and skewness. Bo and Sterken (2007) use $R P_{t}$ (refers to risk premium) to measure the difference between the realized profit rate and risk-adjusted profit rate as follows:

$$
R P_{t}=\left(P T_{t}^{R}-R A R\right)
$$

The manager's risk attitude is indicated by finding how much the standard deviation accounts for the risk premium:

$$
R P_{t}=R C * S D_{t}+\omega * S K E W_{t}
$$

Where $R C$ refers to the measure of the managers' risk attitude of the firm and other notations are as defined before.

Building on utility theory, a positive risk coefficient $(\mathrm{RC}>0)$ signals that a firm's manager is risk-averse, while a negative coefficient $(\mathrm{RC}<0)$ means that the manager is risk-takers. If $\mathrm{RC}$ is insignificant, this means that the firm's manager is risk-neutral.

\subsubsection{Demand Uncertainty Measure}

Following Banker, Byzalov, and Plehn-Dujowich (2014), the demand uncertainty is measured by the standard deviation of ln-changes in revenues $\left(\Delta \ln R E V_{i, t}\right)$ for all valid observations of firm $i$.

\subsection{Estimation Model}

\subsubsection{Anderson et al. (2003) Model}

Following Anderson et al. (2003), the following model is used as a baseline for documenting the average sticky cost behavior:

Model I:

$$
\operatorname{Ln}\left(\frac{O E x_{i, t}}{O E x_{i, t-1}}\right)=\beta_{0}+\beta_{1} \operatorname{Ln}\left(\frac{R e v_{i, t}}{\operatorname{Rev} v_{i, t-1}}\right)+\beta_{2} \times D_{i, t} \operatorname{Ln}\left(\frac{\operatorname{Rev}_{i, t}}{\operatorname{Rev}_{i, t-1}}\right)+\varepsilon_{i, t}
$$

Where:

OEx denotes operating expenses.

Rev denotes total revenue.

$D$ is a constructed dummy variable which equals one when revenue decreases in current period, and zero otherwise.

$t$ denotes time period.

$i$ denotes firm.

$\varepsilon$ denotes random errors.

Following previous studies, the log model is applied. Using the log model will dilute the problem of the great diversity between firms' performances and sizes. Furthermore, the probable heteroscedasticity of cross-sectional and pooled estimation is reduced.

When revenue increases, the coefficient $\beta_{1}$ only will measure the increase because the dummy variable is zero. In periods of revenue decrease the dummy variable equals one which means $\beta_{2}$ will have a value. The percentage of costs decrease that related to a $1 \%$ fall in revenue is measured through the sum of the coefficients $\left(\beta_{1}+\beta_{2}\right)$. Cost stickiness means that the relative increase in costs in response to revenues increase is higher than their relative decrease to an equal decrease in revenue. Therefore, hypothesis $\mathrm{H} 1$ for average stickiness implies that $\beta_{1}>\left(\beta_{1}+\beta_{2}\right)$, or equivalently, $\beta_{2}<0$.

\subsubsection{Extended Anderson et al. (2003) Model}

The estimated risk coefficient $(R C)$ in equation (3) is used to develop a dummy risk variable. If the estimated risk coefficient is positive i.e., the firm's manager is risk-averse, it takes the value of one and zero otherwise. Meanwhile, a demand uncertainty dummy variable is constructed. The demand uncertainty dummy variable equals one if it is higher than the sample median, and zero otherwise. Furthermore, following Banker, Byzalov, and Chen (2013), three control variables are added to the model. They are assets intensity, which is the Ln of assets to sales ratio, the annual rate of GDP growth for Egypt (Note 2), and a previous period decrease dummy which equals one if sales decrease in the previous period and zero otherwise. 
The following model is employed:

Model II:

$$
\begin{gathered}
\ln \left(\frac{O E x_{i, t}}{O E x_{i, t-1}}\right)=\beta_{0}+\beta_{1} \operatorname{Ln}\left(\frac{\operatorname{Rev}_{i, t}}{\operatorname{Rev}_{i, t-1}}\right)+\left(\beta_{2}+\beta_{3} R A V_{i}+\beta_{4} U n c_{i}+\beta_{5} R A V_{i} U n c_{i}+\beta_{6} A I N T_{i, t}+\beta_{7} G D P_{t}+\right. \\
\left.\beta_{8} D_{i, t-1}\right) \operatorname{Ln}\left(\frac{\operatorname{Rev}_{i, t}}{\operatorname{Rev}_{i, t-1}}\right) D_{i, t}+\varepsilon_{i, t}
\end{gathered}
$$

Where:

$R A V_{i}$ is a dummy variable that takes the value of one when $R C$ in model (3) is positive and significant for firm $i$ (manager of the firm is risk-averse), and zero otherwise.

$U n c_{i}$ is the standard deviation of ln-changes in revenues $\triangle L n R E V_{i, t}$ for all valid observations of firm $i$.

$A I N T_{i, t}$ is assets intensity which is the Ln of assets to sales ratio.

$G D P_{t}$ is the annual rate of GDP growth for Egypt.

And remaining variables are as defined before.

Variables definitions are provided in Table 1.

\begin{tabular}{|c|c|}
\hline Variable & Definition \\
\hline $\ln \left(\frac{O E x_{i, t}}{O E x_{i, t-1}}\right)$ & the $\mathrm{Ln}$ of operating expenses ratio of firm $\mathrm{i}$ in year $\mathrm{t}$ relative to year $t-1$. \\
\hline $\operatorname{Ln}\left(\frac{\operatorname{Rev} v_{i, t}}{\operatorname{Rev} v_{i, t-1}}\right)$ & the $\mathrm{Ln}$ of revenues ratio of firm $\mathrm{i}$ in year t relative to year $t-1$. \\
\hline$D_{i, t}$ & $\begin{array}{r}\text { dummy variable which takes the value of one when revenue decreases between two } \\
\text { periods, and zero otherwise. }\end{array}$ \\
\hline$R A V_{i}$ & $\begin{array}{l}\text { dummy variable that takes the value of one when } R C \text { in model (3) is positive and } \\
\text { significant for firm i (manager of the firm is risk-averse), and zero otherwise. }\end{array}$ \\
\hline$U n c_{i}$ & the standard deviation of Ln-changes in revenues $\begin{array}{r}\Delta L n R E V_{i, t} \text { for all valid } \\
\text { observations of firm } i .\end{array}$ \\
\hline$A I N T_{i, t}$ & assets intensity which is the $\mathrm{Ln}$ of assets to sales ratio. \\
\hline$G D P_{t}$ & annual rate of GDP growth for Egypt. \\
\hline
\end{tabular}

Table 1. Variables definitions

\section{Empirical Results}

\subsection{Descriptive Statistics}

Table 2 displays the descriptive statistics for the sample and subsamples. Panel A and panel B represent descriptive statistics for the full sample and the current sales decreasing periods subsample, respectively. Using Bo and Sterken (2007) financial measure and its interaction with high demand uncertainty dummy, two subsamples are created, one for risk-taker firms with high demand uncertainty (panel C), and the second for risk-averse firms with high demand uncertainty (panel D). In the decreasing sales subsample, both means of $\operatorname{Ln}\left(\frac{O E x_{i, t}}{O E x_{i, t-1}}\right)$ and $\operatorname{Ln}\left(\frac{\operatorname{Rev} v_{i, t}}{\operatorname{Rev}_{i, t-1}}\right)$ are negative, however, it is lower for $\operatorname{Ln}\left(\frac{O E x_{i, t}}{O E x_{i, t-1}}\right)$ which reflects sticky cost behavior. Interestingly, the mean of $\operatorname{Ln}\left(\frac{\operatorname{Rev}_{i, t}}{\operatorname{Rev} v_{i, t-1}}\right)$ in risk-taker group is negative (panel C: -0.021 ), and the mean of $\operatorname{Ln}\left(\frac{O E x_{i, t}}{O E x_{i, t-1}}\right)$ in the same group is 
positive (panel C: 0.005); but for the risk-averse group, both means are positive, which implies a higher stickiness in the risk-taker group. Furthermore, the highest mean of cost to sales ratio is 1.112 which belongs to panel C. This implies that risk-taker-high uncertainty firms retain a higher amount of resources. For declining sales observations mean of cost to sales ratio is also high (1.067), which reflects keeping resources during sales decrease periods. Furthermore, the highest standard deviation for net profit to total assets ratio is attributed to the risk-taker firms' group (0.143), while the lowest appears in the risk-averse panel (0.089).

\subsection{Hypotheses Tests}

First, the sticky cost behavior is tested for the whole sample to provide a baseline for the remaining tests. Testing for H1 using Anderson et al. (2003) model for sample firms is presented in Table 3. As expected, the cost stickiness coefficient $\beta_{2}$ is negative and significant at less than $1 \%$ level. The result shows that costs increase by 0.546 when sales increase by $1 \%$ and decrease by $0.348\left(\beta_{1}+\beta_{2}=0.546-0.198\right)$ when sales decrease by $1 \%$. This result is consistent with other results in other countries and in the Egyptian context (e.g., Abdelhamid \& Abulezz, 2019; Ibrahim \& Ezat, 2017).

The results for model (II) are presented in Table 3. As can be seen, the main effect of risk attitude effect on cost stickiness is insignificant. These results are inconsistent with previous literature, except for the tenure variable in Liang et al. (2015). (Note 3)

Furthermore, results are inconsistent with studies that test the managerial overconfidence impact on cost stickiness. Using three different proxies to measure managerial overconfidence, Chen et al. (2013); Qin et al. (2015); and Yang (2015) show a significant association between managerial overconfidence and cost stickiness.

This difference between the current study and previous studies could be justified by two reasons. First, the current study adopts different measures that are not employed by previous literature. Second, the differences in the cultural and business environment between Egypt and other studies.

However, the interaction effect between demand uncertainty and risk attitude is significant. This is reflected by $\boldsymbol{\beta}_{\mathbf{5}}$ which equals 0.398 and is significant at 1 percent level of significance. This documents the importance of demand uncertainty as a moderation variable of the relation of risk attitude and cost stickiness. Higher demand uncertainty means a wider range of possible sales outcomes in the next period. This will induce risk-averse managers to cut resources and bear a certain amount of loss rather than facing various possible outcomes next period which will result in lower cost stickiness.

Table 2. Descriptive statistics

\begin{tabular}{|c|c|c|c|c|c|c|}
\hline \multicolumn{7}{|c|}{ Panel A: Full Sample } \\
\hline Variable & $\mathrm{N}$ & Mean & S. Dev. & Median & Min. & Max. \\
\hline $\operatorname{Ln}\left(\frac{O E x_{i, t}}{O E x_{i, t-1}}\right)$ & 1419 & 0.041 & 0.574 & 0.040 & -2.354 & 2.524 \\
\hline $\operatorname{Ln}\left(\frac{\operatorname{Rev}_{i, t}}{\operatorname{Rev}_{i, t-1}}\right)$ & 1419 & 0.026 & 0.647 & 0.033 & -3.555 & 3.847 \\
\hline$\left(\frac{O E x_{i, t}}{\operatorname{Rev} v_{i, t}}\right)$ & 1419 & 0.984 & 0.844 & 0.901 & 0.013 & 15.804 \\
\hline$\left(\frac{\text { Net Profit }}{i, t}{\text { Total } \text { Assts }_{i, t}}\right)$ & 1419 & 0.069 & 0.114 & 0.062 & -1.167 & 0.484 \\
\hline$U n c_{i}$ & 1419 & 0.325 & 0.307 & 0.245 & 0.053 & 2.003 \\
\hline
\end{tabular}




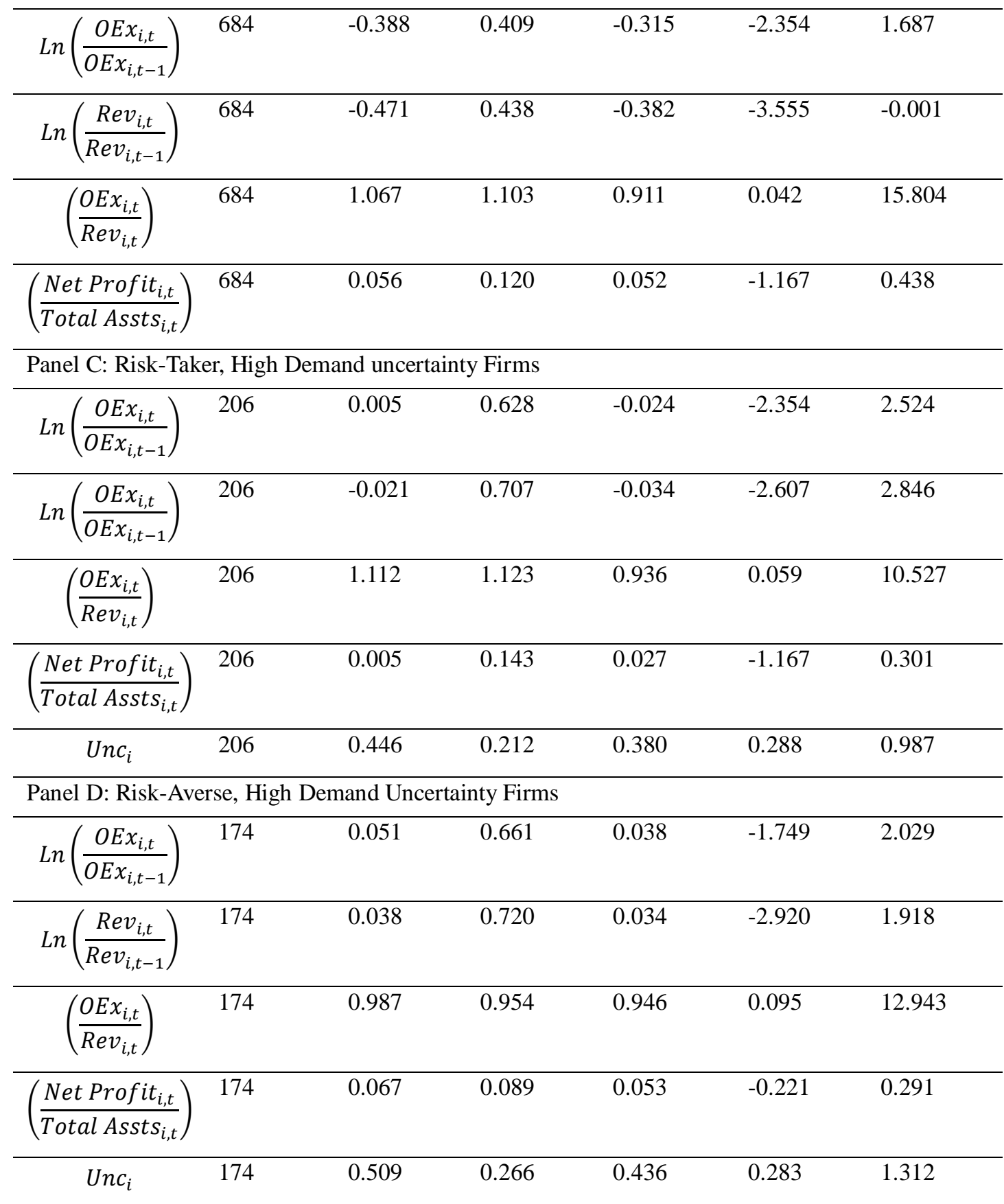

ModelI:

$$
\log \left(\frac{O E x_{i, t}}{O E x_{i, t-1}}\right)=\beta_{0}+\beta_{1} \log \left(\frac{R e v_{i, t}}{\operatorname{Rev}_{i, t-1}}\right)+\beta_{2} \times D_{i, t} \log \left(\frac{\operatorname{Rev}_{i, t}}{\operatorname{Rev}_{i, t-1}}\right)+\varepsilon_{i, t}
$$

Model II:

$$
\begin{gathered}
\ln \left(\frac{O E x_{i, t}}{O E x_{i, t-1}}\right)=\beta_{0}+\beta_{1} \operatorname{Ln}\left(\frac{\operatorname{Rev}_{i, t}}{\operatorname{Rev}_{i, t-1}}\right)+\left(\beta_{2}+\beta_{3} R A V_{i}+\beta_{4} U n c_{i}+\beta_{5} R A V_{i} U n c_{i}+\beta_{6} A I N T_{i, t}+\beta_{7} G D P_{t}+\right. \\
\left.\beta_{8} D_{i, t-1}\right) \operatorname{Ln}\left(\frac{\operatorname{Rev}_{i, t}}{\operatorname{Rev}_{i, t-1}}\right) D_{i, t}+\varepsilon_{i, t}
\end{gathered}
$$


Table 3. Estimation of model (I) and model (II)

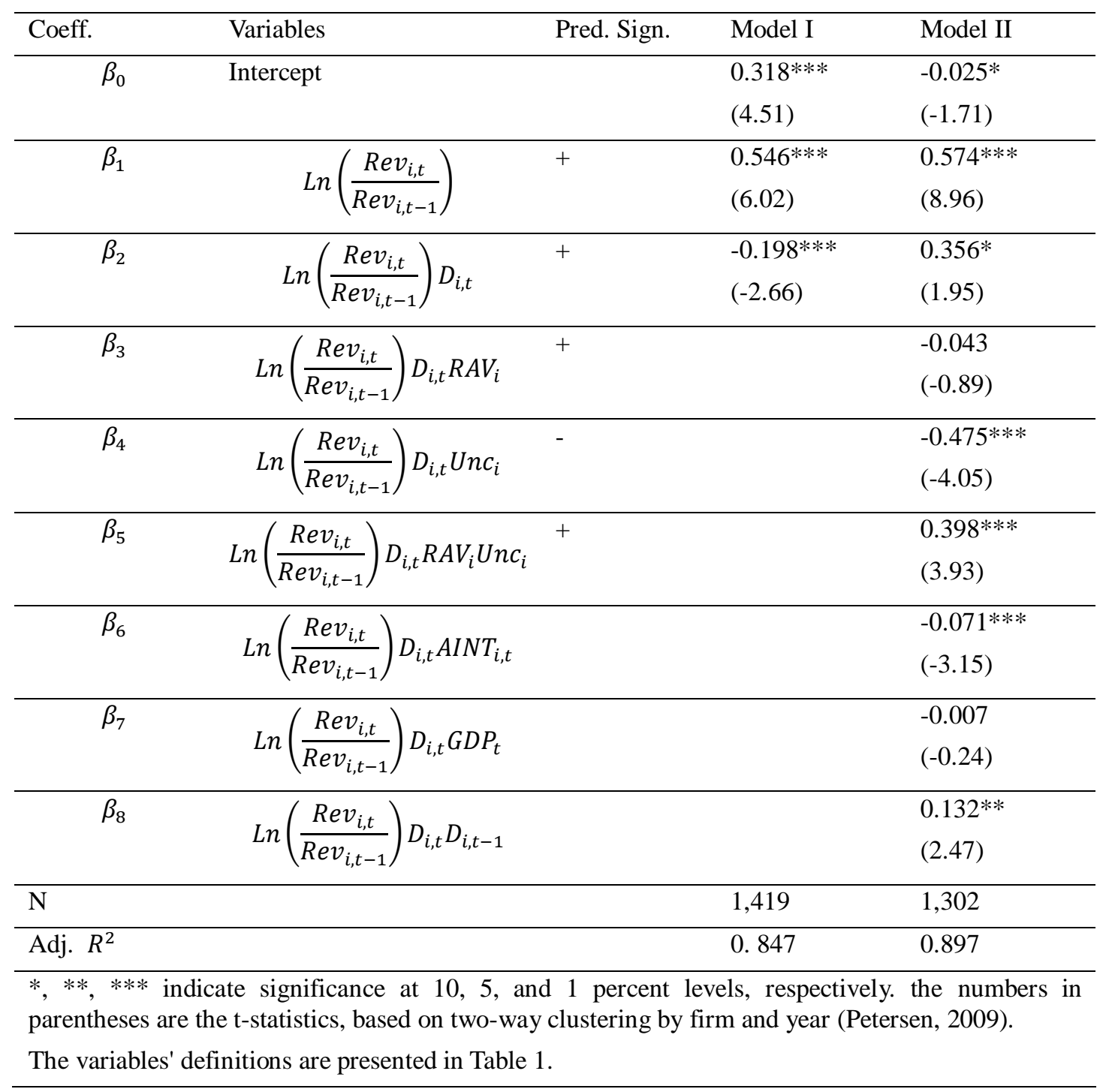

The effect of the interaction between demand uncertainty and risk attitude on investment decisions is stated in previous literature (Bo \& Sterken, 2007; Nakamura, 1999; Rau \& Nickell, 1980; Zeira, 1990). March and Shapira (1987) point out that managers will be neutral in their decision until they operate under risk. Therefore, managers' risk attitude will affect their decisions under risk. Rau and Nickell (1980) argue that risk aversion managers will reduce capacity levels under demand uncertainty. Bo and Sterken (2007) find that managers' reaction to demand uncertainty depends on their risk attitude. Risk-averse managers will cut investment, while risk-taker managers will react to higher demand uncertainty by expanding investment.

\subsection{Robustness Check (Not Tabulated)}

To further check the robustness of results, and to overcome the limitation of considering non-significant $R C$ firms as risk-neutral, the risk attitude dummy variable is replaced with an ordinal measure for risk attitude. If the firm's manager is a risk-taker, i.e., $R C$ in the model (3) is negative and significant it will take the value of one, if the firm's manager is a risk-neutral, i.e., $R C$ in the model (3) is insignificant it will take the value of two, and if the firm's manager is a risk-averse, i.e., $R C$ in the model (3) is positive and significant it will take the value of three. The same effect of the interaction of risk attitude and demand uncertainty variable on cost stickiness remains significant and robust.

Furthermore, the demand uncertainty sample median is used to create a dummy variable that takes the value of one if the demand uncertainty measure for firm $i$ is higher than the sample mean, and zero otherwise. After replacing the 
demand uncertainty measure with this dummy, findings for the interaction between risk preference measure and high demand uncertainty and sticky cost coefficients continue to hold.

Following previous literature that documents that managers with longer tenure will tend to be more risk-averse (Berger, Ofek, \& Yermack, 1997; Caliskan \& Doukas, 2015; Coles, Daniel, \& Naveen, 2006; Doukas \& Mandal, 2018; Liang et al., 2015; Serfling, 2014). Risk attitude measure in model (II) is replaced with the natural logarithm of the number of consecutive years the manager spent in his/her position as the CEO of the firm. By considering the year 2000 as the base year, tenure is calculated for years 2004 to 2017. Consistent with Liang et al. (2015), the main effect of tenure variable is not significant but its interaction with demand uncertainty variable is positive and significant. This contributes to the importance of demand uncertainty as a moderation variable of the relation of sticky cost and managers' risk attitude.

\section{Summary and Conclusion}

Using a sample of 114 Egyptian firms over a 14-year period (2004 - 2017), the current study argues that the manager's risk attitude is an important factor that affects cost stickiness behavior. The main effect of risk

attitude alone on cost stickiness is found to be insignificant, but its interaction with demand uncertainty is significant and consistent with the hypothesis.

The main contribution of the current study to the cost stickiness literature is the documentation of the effect of the interaction between demand uncertainty and risk attitude on cost stickiness. This finding state that demand uncertainty moderates the relation between managers' risk attitude and cost stickiness. High demand uncertainty imposes pressure on managers by increasing potential risks faced by the firm which will lead to high perception of risk. High perception of risk will interact with the manager's attitude toward risk which induces risk-averse managers to cut resources. As a robustness test, risk attitude measure is measured in different ways and results remain unchanged.

The current findings have several implications. First, the current findings demonstrate the active role of one important managers' personality trait (i.e., risk attitude) on firms' operations. The Board of directors should consider the elected managers' risk preferences and how they will react to risky situations. Graham, Harvey, and Puri (2013) find a strong association between managers' behavioral traits and firms' financial policies. Second, the significance of the interaction variable between demand uncertainty and risk attitude implies that firms' operations and the business environment should be considered when selecting the CEO. For example, each stage in the life cycle of the firm may require managers with a specific risk preference which will contribute to the current stage e.g., the manager in the introduction and the growth stages should be more risk-taker than the manager in the declining stage. Third, putting plans and budgets should account for an individual's risk attitude and how this will interact with firms' operations and resources allocation. Fourth, providing good training in risk management for managers may dilute the effect of their personality traits and allow them to make objective decisions. Fifth, developing better incentive systems that consider the manager's risk preference should be attempted to align the interests of managers with stockholders.

The current study has some limitations. First, although managers' risk attitude plays a crucial role in firms' operations, it could be diluted by various factors like firms' policies or corporate governance mechanisms. Second, Bo and Sterken (2007) proxy depends on net profit rate to derive a proxy for manager's risk attitude while net profit depends on various interacted variables. Third, cutting or retaining slack resources in case of sales decrease is not completely under the manager's control. Fourth, Bernile, Bhagwat, \& Yonker (2018) document the effect of the board of directors' diversity on firm's policies which will weaken the manager's risk attitude effect.

Future research may validate the current findings through other measures of manager's risk attitude e.g., questionnaire-based measurement. Moreover, testing whether the type of the firm e.g., private, or governmental could affect the relationship between managers' risk attitude and cost stickiness is worth doing.

\section{Acknowledgments}

I would like to express my deep thanks to Professor Mohamed E. Abulezz and Professor Helal A. Afify, my Ph.D. dissertation supervisors, for their valuable suggestions throughout all research stages. My thanks are also extended to Dr. Ahmed Boghdady for his help in collecting the data for the current research.

\section{References}

Abdelhamid, A. M., \& Abulezz, M. E. (2019, January 4-5). An empirical investigation of the effect of cost structure, demand uncertainty, and exogenous shocks on cost stickiness [Conference presentation]. AAA 2019 Management Accounting Section (MAS) Midyear Meeting, Florida, USA. 
Aboody, D., Levi, S., \& Weiss, D. (2018). Managerial incentives, options, and cost-structure choices. Review of Accounting Studies, 23(2), 422-451. https://doi.org/10.1007/s11142-017-9432-0

Anderson, M. C., Banker, R. D., \& Janakiraman, S. N. (2003). Are selling, general, and administrative costs "sticky"?. Journal of Accounting Research, 41(1), 47-63. https://doi.org/10.1111/1475-679X.00095

Banker, R. D., \& Byzalov, D. (2014). Asymmetric cost behavior. Journal of Management Accounting Research, 26(2), 43-79. https://doi.org/10.2308/jmar-50846

Banker, R. D., Byzalov, D., \& Chen, L. T. (2013). Employment protection legislation, adjustment costs and cross-country differences in cost behavior. Journal of Accounting and Economics, 55(1), 111-127. https://doi.org/10.1016/j.jacceco.2012.08.003

Banker, R. D., Byzalov, D., \& Plehn-Dujowich, J. M. (2014). Demand uncertainty and cost behavior. The Accounting Review, 89(3), 839-865. https://doi.org/10.2308/accr-50661

Banker, R. D., Jin, B., \& Mehta, M. N. (2016). Short-term bonus for CEOs and cost stickiness. Working paper. Temple University.

Berger, P. G., Ofek, E., \& Yermack, D. L. (1997). Managerial entrenchment and capital structure decisions. The Journal of Finance, 52(4), 1411-1438. https://doi.org/10.1111/j.1540-6261.1997.tb01115.x

Bernile, G., Bhagwat, V., \& Yonker, S. (2018). Board diversity, firm risk, and corporate policies. Journal of Financial Economics, 127(3), 588-612. https://doi.org/10.1016/j.jfineco.2017.12.009

Bo, H., \& Sterken, E. (2007). Attitude towards risk, uncertainty, and fixed investment. The North American Journal of Economics and Finance, 18(1), 59-75. https://doi.org/10.1016/j.najef.2006.09.001

Brüggen, A., \& Zehnder, J. O. (2014). SG\&A cost stickiness and equity-based executive compensation: does empire building matter?. Journal of Management Control, 25(3-4), 169-192. https://doi.org/10.1007/s00187-014-0195-5

Caliskan, D., \& Doukas, J. A. (2015). CEO risk preferences and dividend policy decisions. Journal of Corporate Finance, 35, 18-42. https://doi.org/10.1016/j.jcorpfin.2015.08.007

Chen, C. X., Gores, T., \& Nasev, J. (2013). Managerial overconfidence and cost stickiness. Working paper. https://doi.org/10.2139/ssrn.2208622

Chen, C. X., Lu, H., \& Sougiannis, T. (2012). The agency problem, corporate governance, and the asymmetrical behavior of selling, general, and administrative costs. Contemporary Accounting Research, 29(1), 252-282. https://doi.org/10.1111/j.1911-3846.2011.01094.x

Coles, J. L., Daniel, N. D., \& Naveen, L. (2006). Managerial incentives and risk-taking. Journal of Financial Economics, 79(2), 431-468. https://doi.org/10.1016/j.jineco.2004.09.004

Concina, L. (2014). Risk attitude \& Economics. Number 2014-01 of Les Regards, Foundation for an industrial safety culture. $\quad$ Retrieved from https://www.foncsi.org/fr/publications/regards/risk-attitude-and-economics/Viewpoint-risk-attitude-economics. pdf

Cronqvist, H., Makhija, A. K., \& Yonker, S. E. (2012). Behavioral consistency in corporate finance: CEO personal and corporate leverage. Journal of Financial Economics, 103(1), 20-40. https://doi.org/10.1016/j.jfineco.2011.08.005

Dohmen, T., Falk, A., Huffman, D., Sunde, U., Schupp, J., \& Wagner, G. G. (2011). Individual risk attitudes: Measurement, determinants, and behavioral consequences. Journal of the European Economic Association, 9(3), 522-550. https://doi.org/10.1111/j.1542-4774.2011.01015.x

Doukas, J. A., \& Mandal, S. (2018). CEO risk preferences and hedging decisions: A multiyear analysis. Journal of International Money and Finance, 86, 131-153. https://doi.org/10.1016/j.jimonfin.2018.04.007

Fellner, G., \& Maciejovsky, B. (2007). Risk attitude and market behavior: Evidence from experimental asset markets. Journal of Economic Psychology, 28(3), 338-350. https://doi.org/10.1016/j.joep.2007.01.006

Gow, I. D., Ormazabal, G., \& Taylor, D. J. (2010). Correcting for cross-sectional and time-series dependence in accounting research. The Accounting Review, 85(2), 483-512. https://doi.org/10.2308/accr.2010.85.2.483

Graham, J. R., Harvey, C. R., \& Puri, M. (2013). Managerial attitudes and corporate actions. Journal of Financial 
Economics, 109(1), 103-121. https://doi.org/10.1016/j.jfineco.2013.01.010

Hambrick, D. C., \& Mason, P. A. (1984). Upper echelons: The organization as a reflection of its top managers. Academy of Management Review, 9(2), 193-206. https://doi.org/10.5465/amr.1984.4277628

He, D., Teruya, J., \& Shimizu, T. (2010). Sticky selling, general, and administrative cost behavior and its changes in Japan. Global Journal of Business Research, 4(4), 1-10. Retrieved from http://www.theibfr2.com/RePEc/ibf/gjbres/gjbr-v4n4-2010/GJBR-V4N4-2010-1.pdf

Hillson, D., \& Murray-Webster, R. (2017). Understanding and managing risk attitude (2nd ed.). https://doi.org/10.4324/9781315235448

Ibrahim, A. E. A., \& Ezat, A. N. (2017). Sticky cost behavior: evidence from Egypt. Journal of Accounting in Emerging Economies, 7(1), 16-34. https://doi.org/10.1108/jaee-06-2014-0027

Kahneman, D., \& Tversky, A. (1979). Prospect theory: an analysis of decision under risk. Econometrica, 47(2), 263-291. https://doi.org/10.2307/1914185

Kama, I., \& Weiss, D. (2013). Do earnings targets and managerial incentives affect sticky Costs?. Journal of Accounting Research, 51(1), 201-224. https://doi.org/10.1111/j.1475-679X.2012.00471.x

Kitching, K., Mashruwala, R., \& Pevzner, M. (2016). Culture and cost stickiness: A cross-country study. The International Journal of Accounting, 51(3), 402-417. https://doi.org/10.1016/j.intacc.2016.07.010

Liang, S., Zhao, G., \& Wang, N. (2015). Managers' personal characteristics, bank supervision, and cost stickiness. China Accounting and Finance Review, 17(4), 1-51. https://doi.org/10.7603/s40570-015-0011-0

Malmendier, U., \& Nagel, S. (2011). Depression babies: Do macroeconomic experiences affect risk taking?. The Quarterly Journal of Economics, 126(1), 373-416. https://doi.org/10.1093/qje/qjq004

Malmendier, U., Tate, G., \& Yan, J. (2011). Overconfidence and early-life experiences: The effect of managerial traits on corporate financial policies. The Journal of Finance, 66(5), 1687-1733. https://doi.org/10.1111/j.1540-6261.2011.01685.x

March, J. G., \& Shapira, Z. (1987). Managerial perspectives on risk and risk taking. Management Science, 33(1), 1404-1418. https://doi.org/10.1287/mnsc.33.11.1404

Miller, K. D., \& Chen, W. R. (2004). Variable organizational risk preferences: Tests of the March-Shapira model. Academy of Management Journal, 47(1), 105-115. https://doi.org/10.2307/20159563

Nakamura, T. (1999). Risk-aversion and the uncertainty-investment relationship: A note. Journal of Economic Behavior and Organization, 38(3), 357-363. https://doi.org/10.1016/S0167-2681(99)00015-3

Prendergast, C., \& Stole, L. (1996). Impetuous youngsters and jaded old-timers: Acquiring a reputation for learning. Journal of Political Economy, 104(6), 1105-1134. https://doi.org/10.1086/262055

Qin, B., Mohan, A. W., \& Kuang, Y. F. (2015). CEO overconfidence and cost stickiness. Management Control \& Accounting, 2, 26-32.

Rau, N., \& Nickell, S. J. (1980). The investment decisions of firms. Economica, 47(188), 481. https://doi.org/10.2307/2553404

Rego, L. L., Billett, M. T., \& Morgan, N. A. (2009). Consumer-based brand equity and firm risk. Journal of Marketing, 73(6), 47-60. https://doi.org/10.1509/jmkg.73.6.47

Rieger, M. O., Wang, M., \& Hens, T. (2015). Risk preferences around the world. Management Science, 61(3), 637-648. https://doi.org/10.1287/mnsc.2013.1869

Rohrmann, B. (2005). Risk attitude scales: concepts, questionnaires, utilizations. Project Report. University of Melbourne. Retrieved from http://rohrmannresearch.net/pdfs/rohrmann-racreport.pdf

Serfling, M. A. (2014). CEO age and the riskiness of corporate policies. Journal of Corporate Finance, 25, 251-273. https://doi.org/10.1016/j.jcorpfin.2013.12.013

Weber, E. U. (2010). Risk attitude and preference. Wiley Interdisciplinary Reviews: Cognitive Science, 1(1), 79-88. https://doi.org/10.1002/wcs.5

Wiersma, E. (2012). The impact of the reward structure on stickiness. Working paper. https://doi.org/10.2139/ssrn.1668758 
Yang, D. (2015). Mergers, CEO hubris, and cost stickiness. Emerging Markets Finance and Trade, 51(sup5), S46-S63.

Zeira, J. (1990). Cost uncertainty and the rate of investment. Journal of Economic Dynamics and Control, 14(1), 53-63. https://doi.org/10.1016/0165-1889(90)90005-2

\section{Notes}

Note 1. The two-way clustered standard error is not applied as the time series is very short compared to the number of observations.

Note 2. GDP is obtained from the world bank website.

Note 3. In a robustness test, tenure is used as a measure for risk attitude and similar results are obtained.

\section{Copyrights}

Copyright for this article is retained by the author(s), with first publication rights granted to the journal.

This is an open-access article distributed under the terms and conditions of the Creative Commons Attribution license (http://creativecommons.org/licenses/by/4.0/). 